\title{
ANAESTHESIA IN GENERAL PRACTICE
}

\author{
This is one of a series of articles, contributed by invitation
}

\section{PRE-OPERATIVE TREATMENT AND PREMEDICATION}

BY

\section{R. MACHRAY, M.B., B.S.}

The present article outlines the measures that it is desirable to take in the preparation of a patient for operation in so far as these come under the control of the anaesthetist. The extent of preparation necessary or possible will naturally vary widely, but the guiding principle should be that the patient comes to the theatre in the best possible condition of physical health and mental rest, so that he will the better be able to resist the disturbances that the disease, its operative treatment, and the anaesthetic produce. The period, therefore, between the decision to operate and the operation itself should be utilized with this in mind.

\section{General Rules}

The length of time devoted to pre-operative measures will vary with the urgency of the operation. When circumstances allow, it may be advisable for the patient to spend several weeks of easy life in pleasant surroundings with special attention to diet and sleep. There will be cases in which, although the need for operation is urgent, a better result will be obtained if prolonged and complete rest in bed with appropriate medical treatment is enforced. Such conditions may arise from the nature of the disease itself or from some intercurrent affection. It is obviously wise to postpone until better weather operating on patients who are "chesty every winter," and, in general, extremes of temperature and fog should be avoided. Dental sepsis has a definite influence on pulmonary complications. It should therefore be eradicated if there is sufficient time for any possible reaction to subside; otherwise much may be done with brushing and mouth washes. These questions are usually outside the anaesthetist's province, but if the anaesthetist is also the general practitioner they will need consideration.

Coming now to more immediate measures, adequate rest and opportunity for an unhurried preparation are essential, while the early morning, say 8 to 9 o'clock, is the best time for the operation itself. These things can best be arranged for in most instances if the patient enters the nursing home early the previous evening; after a good night's sleep he then has not to wait long for the final preparation before basal narcosis or the anaesthetic itself is begun. In formidable operations and where lengthy preparation is necessary, and in the case of the old and feeble, more time should be allowed and there should be a complete absence of hurrying. Such a course will always be found worth while. In comparatively trivial operations, however, it is permissible for the patient to enter the nursing home only a few hours before the operation, if this takes place in the afternoon.

\section{Purgation}

Where no action of the bowels will take place for two or three days, as in abdominal operations, it is obviously desirable that the alimentary canal should be reasonably empty, and in other cases it will usually make the patient more comfortable. But this emptying should be done by the most gentle method possible and vigorous purgation avoided. Many of the drugs employed are mucosal irritants and not only will produce diarrhoea and a disturbed night but will increase the post-operative discomfort and favour subsequent distension. Another objection is that vigorous purgation will tend to dehydration and acidosis. Frequently the patient will be able to say which aperient and what dose suit him best, and also how long it takes to act: the last is important, as an unbroken night must be assured and the bowels must be opened at least three hours before operation. A suitable purgative is infusion of senna. Sometimes the least disturbing results will be obtained from a combination of mild purgation and an enema. An enema alone will be indicated in two circumstances: first, when there is insufficient time for an aperient to act (although the patient can be instructed to take it at a suitable time before entering the nursing home); secondly, when avertin is to be given. Here success depends so much on complete retention that, unless several hours can elapse after the action from the purgative, it is unwise to risk an irritated bowel and better to rely on a skilfully administered soap-and-water enema. Even this should be given four hours before the administration of avertin. Pelvic operations need a more elaborate preparation, which is usually dictated by the surgeon.

\section{Value of Glucose}

Where dehydration and starvation are present the loss should be made good by giving saline and glucose, by the rectal route if necessary. Pre-operative glucose is valuable in the prevention of post-anaesthetic acidosis. It should be prescribed especially when there is any evidence of deranged liver function and when previous anaesthetics have been followed by much vomiting. In normal cases it probably has no effect, but since it also has no ill effect it should be given in all cases except the most trivial. Recommended doses vary_ widely, but probably two to three ounces confer the maximum benefit and should be taken in lemonade with the evening meal. Diabetic patients will need special treatment and a dosage of insulin and'glucose, worked out for each case.

\section{Sleep}

A good night's sleep is of great importance, and there will not be many patients who can manage this without assistance. A sleepless night will not only cause great mental distress but will be wearing to the patient's physical condition. Even if he has been sleeping well previously it is better to order a sedative. The drug and dose will vary with the temperament, but adequate dosage is essential. Here, again, the patient may be able to suggest a drug that suits him or, what is more important, drugs that have no effect or are upsetting. Aspirin and bromides are of help but not certain enough for routine use. Nembutal, grains $1 \frac{1}{2}$, is reliable, and may be combined with aspirin, grains 10. Medinal grains 5 to $7 \frac{1}{2}$ is more powerful but does not suit everyone. The patient should retire to bed before 10 p.m. and immediately take the sedative, and he should sleep until about 5 to 6 o'clock. If he wakes early and feels hungry he should be allowed a cup of tea and 
b:scuits. It may be mentioned that should the operation be timed for later in the day light meals can be taken until as late as possible-say, until three hours before. Hunger is bad and starvation may lower the liver glycogen.

Small children will as a rule sleep well with a certain amount of coaxing, but if their surroundings disturb them, and especially if they know they are to have an operation, sleep may be impossible without help. Chloral is a useful sedative in doses of 1 grain for each year of life, with syrup. aurantii 30 minims and water to 1 drachm.

\section{Premedication}

Several factors need to be considered in deciding what drugs to use for premedication-the temperament of the patient, his general condition, and the anaesthetic it is proposed to employ. The indications for some form of pre-operative sedation fall into two categories. The first is the removal of the unpleasant sensation of being taken conscious to the theatre and there being anaesthetized with something evil-smelling over the face. Even the placid who seem to approach operations with equanimity may suffer much mental distress, while with nervous patients the removal of this dread may be an important factor in the success of the operation. A pre-operative sedative will also reduce the amount of inhalational anaesthetic required, and if suitably selected will make it possible to conduct an operation under nitrous oxide and oxygen when this would otherwise be impossible. It will reduce ccnsiderably the amount of ether required in deep anaesthesia for upper abdominal operations. It is necessary, however, to exercise judgement in the selection of cases and in the amount of sedation employed. The action of the drugs used is long and cannot well be reversed once they have been administered. The disadvantages can be summarized as follows :

1. The possibility of the airway becoming obstructed as the jaw relaxes, a condition made less obvious by the quiet respiration, necessitates skilled watching after administration.

2. The depth of narcosis, at first satisfactory, may, if shock develops, become dangerously deep.

3. In such-cases insufficient aeration may be present afterwards from respiratory depression, although this may have been controlled during the operation. This, too, makes skilled nursing necessary.

4. Such a period of reduced pulmonary ventilation will tend to increase the risk of respiratory complications, while a prolonged absence of the cough reflex may have the same risk.

5. The possibility of derangement of liver function by barbiturates, and possibly by avertin, in cases of hepatic insufficiency.

Unless he has some experience in pre-operative medication the anaesthetist would do well to keep within the recognized scale of doses-or below, when age, weight, or feebleness suggest caution. In any event sedation should not be pushed to the stage of full anaesthesia (evipan and pentothal are not now being considered), but this should be completed by some inhalational method more under minute-to-minute control. Some obstetricians consider it unwise to give anything but atropine before Caesarean section because of the depressing action on the foetal respiratory centre.

\section{Atropine}

The most commonly used drug is atropine. It decreases the secretion of mucus and paralyses the vagus, thus diminishing one of the dangers of chloroform. It has no sedative action. For patients over the age of 2 years the dose is grain 1/100. Below this age it should be prescribed as follows: up to 6 months grain $1 / 300 ; 6$ to 12 months grain $1 / 200 ; 1$ to 2 years grain $1 / 150$. Atropine should be given in all cases except in operations of only a few minutes' duration and in those in which hyoscine is being used (hyoscine has a similar action to atropine in reducing secretion). Hyoscine is better substituted for atropine in cases of hyperthyroidism in view of the metabolic stimulation of atropine.

\section{Morphine and Hyossine}

Pre-operative sedatives fall into two categories: those producing drowsiness and amnesia, and those producing unconsciousness. The first category is represented by morphine and hyoscine, which together form an extremely good combination. The standard dose for adults is: morphine grain $1 / 6$ to $1 / 4$; hyoscine grain $1 / 150$. In some cases the patients will be asleep when the anaesthetic is started, but short of this there will be drowsiness and absence of anxiety and afterwards a partial or complete amnesia. Omnopon gives rather better results than morphine: the usual dose-grain $1 / 3$-is the equivalent of rather more than 1/6 grain of morphine.

There are few contraindications but some drawbacks. In view of the respiratory depression-not great, however, and usually more noticeable during the anaesthetic than before-pure chloroform should not be used and avertin is better avoided. For the same reason open ether is sometimes more difficult to give. The shallow breathing and tendency to apnoea make it difficult for a sufficient quantity of anaesthetic to be introduced. The signs of anaesthesia are less obvious and the anaesthetist may be misled by a condition similar to chloroform sleep. But with experience this can be overcome. Carbon dioxide is a valuable help. These objections apply to all pre-operative sedation and make the use of some form of closed anaesthesia with its greater control of respiration desirable.

Morphine and hyoscine are safe, and will be found the most suitable agents for routine use before general and spinal anaesthesia. The doses recommended here are as a rule sufficient, but may be exceeded in suitable cases. The injection should be given one hour before the operation and preferably with the patient on the stretcher or trolley. The room should be darkened and kept quiet, as with all forms of sedation. The action of morphine and hyoscine may be supplemented by an intravenous injection of one of the short-acting barbiturates-evipan or pentothal-which should be given immediately before induction of the inhalational anaesthetic and should be pushed to the stage of profound sleepiness just short of surgical anaesthesia. When either of these two drugs is to be used as the main anaesthetic a similar injection of morphine and hyoscine will be found to improve the anaesthesia and reduce the dosage.

\section{Basal Hypnosis}

Paraldehyde is the safest basal hypnotic. In normal doses it does not depress respiration and the cough reflex is not abolished. Since it is excreted in the breath it has no effect on liver or kidneys. Its smell is noticed least by the patient. It is administered in ten times its bulk of saline as a rectal injection with the patient on the left side. The standard dose is 1 drachm per stone of body weight and should be given one hour before operation. Young children, the elderly, and the sick, should receive about 20 per cent. less. Results are good but conscious- 
ness is not always lost, although there will be no recollection of this.

Avertin is the most reliable in its hypnotic action. Its dosage ( 0.1 gramme per kilogramme of body weight) and method of preparation can be obtained from a table supplied by the makers and should be adhered to. Obese and elderly patients require a smaller dose-say threequarters-while the maximum should be 8 grammes. In cases of doubt it is best to run in three-quarters of the selected dose and after a quarter of an hour to use the remainder if consciousness has not been lost. It should be given half an hour before operation and the patient be kept on the side until the anaesthetic is started. This will minimize the risk of obstruction as the jaw relaxes.

\section{THE SHANGHAI BOMBARDMENTS}

Any scepticism that may have been felt regarding newspaper reports on the effects of Japanese bombing of densely populated Chinese cities is dispersed by firsthand accounts of the experiences of resident British doctors which are now reaching England. The plight of the unfortunate Chinese civilians and the immense difficulties of providing adequate medical aid for the stricken and homeless are now more fully realized in this country and on the Continent. The League of Nations has voted a sum of $£ 250,000$ for medical services in China. Following an appeal by the Archbishop of Canterbury and other leading men a national fund has been opened for the relief of distress under the auspices of the China Association, the British Red Cross Society, and the Conference of British Missionary Societies. Meanwhile, pending the arrival of reinforcements of medical personnel and supplies, the energies and resources of doctors and hospitals in Shanghai, Canton, and other Chinese cities are sorely strained.

\section{Care of Wounded Civilians}

In the Shanghai bombardments the task of dealing with the wounded civilians fell largely to the Lester Chinese Hospital. This institution, founded in 1844 , is staffed by . missionary doctors and nurses appointed by the London Missionary Society and also by Chinese members of both professions. There are normally 230 beds, and 4,000 in-patients are treated annually, while the number of new out-patients reaches 62,000 . Since other hospitals had to be evacuated for military reasons, while the emergency and Red Cross hospitals were entirely reserved for the soldiery, the influx of wounded civilians into the Lester Hospital was particularly heavy. Some measure of relief was afforded by the conversion to a temporary hospital of the Lester Institute, normally devoted to laboratory work and research. In addition to the great number of direct victims of the bombardments, many of whom suffered from severe cranial or abdominal wounds, other unfortunates were brought to hospital, especially Koreans, who, suspected of being Japanese spies, had been severely handled by the crowd. The appalling effects of modern explosives in densely populated areas are evidenced by the statement that the bursting of one single shell resulted in the death of two hundred people.

Among casualties brought to the Lester Hospital was a man whose body, completely severed across the middle, was still held together by his almost uninjured clothes. In another case a Chinese mother was blown to pieces, while the twin babies in her arms escaped with a few scratches. Less tragic, but grimly humorous, was the case of a woman whose leg had to be amputated. On regaining consciousness she burst into tears, bemoaning the loss of thirty dollars which had been hidden in the stocking of the severed limb.

Apart from the great influx of major surgical cases, many other factors increased the difficulties of the hos- pital. The staff was depleted by the holiday season. As a precaution against fires the gas supply had to be cut off. The general disorganization consequent upon the bombardment made it difficult to obtain focd and other supplies, while a plague of flies from the corpse-littered destroyed areas caused a heavy incidence of dysentery.

These accounts of the troubles encountered in Shanghai in dealing with civilian victims of artillery, and especially aerial, bombardments give a painful foretaste of the conditions which may be expected in our own cities in the event of another European conflagration. Similar problems will have to be met, and it is important that measures for dealing with the civilian victims of aerial warfare should be perfected, as far as possible, in peace time. This point has been stressed in our correspondence columns.

In the issue of October 2 we printed a letter received by the Secretary of the British Medical Association from Dr. R. C. Robertson of the Lester Institute, Shanghai. The letter quoted a cablegram from the British doctors of that city appealing to the B.M.A. to exert its influence to prevent the carnage caused by bombing.

\section{CONGRESS FOR EXPERIMENTAL CYTOLOGY ZURICH, AUGUST, 1938}

According to the decisions taken at the fourth Congress in Copenhagen, the fifth International Congress for Experimental Cytology will be held in Zurich, Switzerland, during the week August 7 to 12,1938 . The sixteenth International Physiological Congress and the International Veterinarian Congress will be held in Zurich too, on August 14 to.18 and August 21 to 25 respectively.

The proceedings of the Cytological Congress are not to be divided in sections, but will be organized in the following way: scientific sessions will take up seven half-days; two afternoons are reserved for demonstrations, and during one afternoon there will be an excursion. Special subjects are to be treated at each session, opening "with a general review, to which one or two supplementary reviews may be added. Reprints of these papers will be sent to the members of the Congress at their home address, or-if very late-will be handed over to the members at the opening sessions. Copies of the individual papers are likewise to be distributed before the sessions, the main object of the Congress being the discussion of cytological topics of special interest.

In agreement with the International Committee the Local Committee has chosen the following subjects for review: epithelium in culture and in the organism; structure of chromosømes; mechanism of mitosis; cancer cells and normal cells; experimental research on cytology and viruses; ultrastructure of the protoplasm and its products; chemistry of the cell. These reviews are calculated to cover the seven scientific sessions in the order indicated above. The names of the reviewers will be published in the second preliminary programme. The individual papers must be registered at the Congress Bureau before April 15, accompanied by a summary not to exceed half a page in the Archiv f. exp. Zellforschg. (the address of the Congress Bureau is, Prof. W. von Möllendorf, 9, Plattenstrasse, Zurich). The Local Committce will decide in each case whether it is possible to accept papers entered later than April 15.

Further information about the Congress may be had through Professor W. von Möllendorf or the honorary secretary for the Society, Harald Okkels, M.D., Institute for Pathological Anatomy, University of Copenhagen, Denmark.

The Board of Control (Metropole Buildings, Northumberland Avenue, W.C.2) has issued a revised list of medical practitioners in England and Wales who have been approved by the Board for the purpose of making recommendations under Sections 1 (3) and 5 (3) of the Mental Treatment Act, 1930. The names are given first in alphabetical order with full addresses, and are then regrouped geographically. 